\title{
Sleep Quality among Hispanics of Mexican Descent and Non-Hispanic Whites: Results from the Sleep Health and Knowledge in US Hispanics Study
}

\author{
Xavier Soler $^{1 *}$, Carolina Diaz-Piedra ${ }^{2}$, Wayne A. Bardwell ${ }^{1}$, Sonia Ancoli-Israel ${ }^{1}$, \\ Lawrence A. Palinkas ${ }^{1,3}$, Joel E. Dimsdale ${ }^{1}$, Jose S. Loredo ${ }^{1}$ \\ ${ }^{1}$ University of California San Diego, San Diego, USA \\ ${ }^{2}$ University of Granada, Granada, Spain \\ ${ }^{3}$ University of Southern California, Los Angeles, USA \\ Email: ${ }^{*}$ xsoler@ucsd.edu
}

Received April 1, 2013; revised May 3, 2013; accepted May 10, 2013

Copyright (C) 2013 Xavier Soler et al. This is an open access article distributed under the Creative Commons Attribution License, which permits unrestricted use, distribution, and reproduction in any medium, provided the original work is properly cited.

\begin{abstract}
Objectives: To investigate differences in sleep quality between Hispanics of Mexican descent (HMD) and Non-Hispanic Whites (NHW) and evaluate the effect of acculturation to the US lifestyle in sleep health. We hypothesize that the detrimental effect of acculturation on health outcomes will impact sleep quality among HMD. Design: We performed a population-based random digit dialing telephone survey to determine sleep quality in HMD and NHW. We collected from 3667 subjects, demographics, previous diagnosis of depression or anxiety, past treatment for sleep disorders, the Pittsburgh Sleep Quality Index (PSQI) and the Short Acculturation Scale for Hispanics. Results: The prevalence of poor sleep quality (PSQI $>5$ ) was $64.4 \%$ for HMD and $64.3 \%$ for NHW $(p=0.93)$. A prior diagnosis of depression or anxiety was an independent predictor of poor sleep quality in both groups (OR 3.4 and 2.7 for HMD and NHW. Ethnicity was not a predictor of poor sleep quality in HMD or NHW. Acculturation was not a predictor of poor sleep quality in HMD. However, highly acculturated young HMD males had significantly more prevalence of poor sleep quality compared to NHW ( $64.8 \%$ vs. $49.8 \%, p<0.001)$. Conclusion: The absence of sleep quality differences in a large sample of HMD and NHW living in San Diego County is contrary to current data of having poorer sleep quality among Latinos. We found that neither ethnicity nor acculturation were predictors of poor sleep quality in HMD. However, we demonstrated a highly prevalent poor sleep quality among the two ethnic groups. The finding of significantly lower sleep quality in young highly acculturated HMD men may represent the heterogeneity of ethnicity related to sleep. Programs to improve sleep quality in subjects with depression and/or anxiety, and in young highly-acculturated HMD seems warranted.
\end{abstract}

Keywords: Sleep Quality; Race/Ethnicity; Acculturation; Hispanics; Latinos; Mexican-Americans; PSQI

\section{Introduction}

Sleep is restorative in daily functioning [1] and is intrinsically important in sustaining physical and psychosocial well-being that theoretically is thought to be dependent of ethnicity and culture [2,3]. Furthermore, sleep disorders are linked to poor mental and physical health and directly impact quality of life [4-8]. Prior studies have suggested ethnic differences in sleep-related disorders such as obstructive sleep apnea, restless legs syndrome, insomnia, and in sleep continuity and architecture [9-19]. The majority of sleep research has been conducted in

${ }^{*}$ Corresponding author.
Non-Hispanic Whites (NHW), and to a lesser extent in African-Americans and Asians. Therefore, these results cannot be easily generalized to other ethnic groups such as Hispanics, the second largest ethnic group and the fastest-growing minority in the United States [20,21]. An understanding of the epidemiology of sleep disorders among different ethnic groups is of key importance to appreciate the links between sleep problems and cardiovascular disorders such systemic hypertension, stroke or metabolic syndrome, quality of life, and the use of medical care among general populations [22]. As part of the Sleep Health and Knowledge in US Hispanics project (aimed at characterizing sleep disorders and health-re- 
lated knowledge of Hispanics of Mexican descent (HMD) and NHW in San Diego County), we studied ethnic differences on sleep quality on both groups. Because ethnic differences in health outcomes may be attributable to both biological and environmental factors, we also wished to determine the role of acculturation in sleep quality in this population, questions that are relevant for future public health policies planning on these groups. Assuming that acculturation may negatively impact health outcomes, [23] we hypothesize that HMD will have significantly poorer sleep quality compared to the group of NHW measured with the PSQI.

\section{Methods}

\subsection{Subjects}

From January 2007 to September 2009, a total of 149,552 phone numbers were randomly dialed from which 14,162 households responded and showed interest in participating in the telephone survey (9.5\% of response rate). Of these, 10,495 (74\%) were not qualified to participate because no one in the household was HMD or NHW or over quota for NHW in 59 cases. To be included in the study, subjects should have $>18$ years old, self-identified as HMD or NHW ethnic group, and living in San Diego County, California. A total of 3667 subjects were analyzed (1754 HMD and 1913 NHW). Informed consent was obtained over the telephone. Only subjects with complete and valid responses to the Pittsburgh Sleep Quality Index (PSQI) were included in the analyses. Cases were excluded when discrepancies were found in the reports. For instance, if the subject reported habitual sleep duration longer than the habitual sleep period (i.e. patient reporting to sleep usually 9 hours, and in following question answered going to bed at $11 \mathrm{pm}$ and waking up at $6 \mathrm{am}$, so time in bed is 7 hours total). Also, subjects reporting sleeping time greater than 12 hours were excluded. Final analyzed sample was 3138 subjects. The study was approved by the University of California San Diego Human Research Protections Program.

\subsection{Study Design}

The Waksberg random digit dialing procedure was used for recruitment [24]. This method is used for population-based epidemiological studies. A computerized database randomly assign and call phone numbers based in a previously criteria of interest. It permits to accurately select populations having certain characteristics such gender or ethnicity. The survey was administered by trained, bilingual, culturally competent telephone interviewers (California Survey Research Services, Inc., Van Nuys, CA) utilizing a computer assisted telephone interview system. In order to adjust for the racial/ethnic dis- tribution of the San Diego County population, zip codes with higher concentrations of Mexican Americans were over sampled. Once a qualifying household was identified a randomization procedure was utilized to recruit only one adult participant per household.

The survey took approximately 40 minutes to complete. We included: 1) demographics; 2) the sleep quality questionnaire (PSQI) (25); 3) prevalence of smoking, alcohol use, coffee use; 4) a previous diagnosis of anxiety and/or depression ("have you ever been told that you have had anxiety and/or depression?"); 5) and existence of sleep disorder treatments ("have you ever been treated for a sleep disorder?'). HMD subjects were also asked to take the Short Acculturation Scale for Hispanics [25]. The telephone questionnaires were administered in English or Spanish based on participant's preference.

\subsection{Evaluation of Sleep}

The PSQI assesses subjective sleep quality and sleep disturbances over the previous month. It consists of 19 items evaluated over 7 domains that include subjective sleep quality, sleep latency, sleep duration, habitual sleep efficiency, sleep disturbances, use of sleep medicationsand daytime dysfunction. Domains are scored on a 0 to 3 scale where 3 indicate severe impairment. The 7 subscale scores are then totaled to provide a global PSQI score, which has a range of $0-21$, with higher scores indicating worse sleep quality [26]. The PSQI has established acceptable reliability (Cronbach's alpha $=0.82$ 0.89 ) and validity (specificity rates to the clinical diagnosis of insomnia: $80 \%-100 \%$ ). Global scores $>5$ were interpreted as an indicator of poor sleep quality. Both English and Spanish versions of the PSQI were available for administration. The PSQI has been translated into Spanish by various authors and validated in Spanish speaking populations in Spain, [27] Colombia, [28] and Mexico [29]. Each translation varies slightly. We made minor changes to some of the expressions to adapt the instrument to a telephone interview format and to the Mexican American population. For example, question 5c, we used "baño" instead of "servicio" to denote the bathroom.

\subsection{Evaluation of Acculturation Level}

Those subjects identifying themselves as HMD were further asked to take the Short Acculturation Scale for Hispanics, a 12 -item validated instrument, available in both English and Spanish, which provides a global numerical measure of acculturation to the American lifestyle based on language familiarity and usage, language preference in media interactions, ethnic social and personal interaction and identity. HMD participants were classified as highly acculturated or leastacculturated based 
on whether their acculturation score fell above or below the group median. Higher scores suggest more acculturation.

\subsection{Statistical Analysis}

Statistical analyses were performed using SPSS 17.0 for Windows (SPSS Inc., Chicago, IL). Descriptive statistics for continuous variables were expressed as means with standard deviations, and categorical data were described as frequencies and percentages. "Don't know" and "Refuse to answer" responses were set to missing values and excluded from analyses. Student $t$-tests were used to compare mean values of PSQI. Pearson's Chi-Square test was used to compare frequency data. For each ethnic group, anxiety, depression, gender, age and use of tobacco, alcohol and/or coffee scores were entered in to logistic regression models taking PSQI score value $(\leq 5$ vs. $>5$ ) as the dependent variable. Acculturation was included in the Hispanic model. Post hoc analyses of prevalence of poor sleep quality were performed on HMD data dividing the population by the median age into young and older adults ( $\leq 47$ and $\geq 48$ years, respectively). A $p$ value $<0.05$ was regarded as statistically significant.

\section{Results}

\subsection{Socio-Demographic Variables}

Subject characteristics appear in Table 1. From the 3138 subjects that were analyzed (1445 HMD and 1693 NHW), 1471 were males and 1667, females. HMD were significantly younger than NHW $(41.5 \pm 15.8$ years old vs. 55.4 \pm 17.2 years old, $p<0.001)$. Table 2 shows the subject characteristics of highly acculturated vs. least acculturated HMD. In general, highly acculturated Hispanics were younger, had a higher prevalence of use of alcohol and lower prevalence of use of caffeinated beverages. There was no difference in BMI, prevalence of smoking, prior treatment for sleep disorders or previous diagnosis of anxiety and/or depression between highly and least acculturated Hispanics.

\subsection{Subjective Sleep Quality}

Table 3 depicts reported sleep quality as measured by the PSQI in both HMD and NHW. The proportion of subjects reporting poor sleep quality was not significantly different between HMD and NHW (64.4\% and 64.3\% for HMD and NHW respectively, $p=0.933$ ). There was also no significant difference in the mean PSQI global score between ethnic groups $(6.65 \pm 4.1$ for HMD vs. $6.67 \pm$ 4.1 for NHW, $p=0.904)$. On average, women reported significantly worse sleep quality than men (PSQI global scores $7.0 \pm 4.2$ vs. $6.2 \pm 3.8, p<0.001$ ). The proportion of HMD reporting poor sleep quality among the highly
Table 1. Hispanics of Mexican descent and non-Hispanic Whites characteristics.

\begin{tabular}{lccc}
\hline & HMD $^{\mathbf{a}}$ & $\mathbf{N H W}^{\mathbf{b}}$ & \\
\hline $\mathbf{n}$ & $\mathbf{1 4 4 5}$ & $\mathbf{1 6 9 3}$ & $p$ \\
\hline Gender (\% Male/Female) & $42.5 / 57.5$ & $50.6 / 49.4$ & $<0.001$ \\
Age (years, mean \pm SD) & $41.5 \pm 15.8$ & $55.4 \pm 17.2$ & $<0.001$ \\
BMI $^{\mathrm{c}}\left(\mathrm{kg} / \mathrm{m}^{2}\right.$, mean \pm SD) & $28.1 \pm 6.5$ & $27.2 \pm 5.7$ & $<0.001$ \\
Smokers (\%) & 15.2 & 19.1 & 0.005 \\
Alcohol consumers (\%) & 33.1 & 51.2 & $<0.001$ \\
Caffeine consumers (\%) & 64.3 & 65.5 & 0.469 \\
Sleep disorders treatment (\%) & 8.7 & 14.9 & $<0.001$ \\
Depression/anxiety diagnosis (\%) & 27.6 & 31.4 & 0.061 \\
\hline
\end{tabular}

${ }^{\mathrm{a}}$ Hispanics of Mexican descent; ${ }^{\mathrm{b}}$ Non-Hispanic Whites; ${ }^{\mathrm{c}}$ Body mass index.

Table 2. Least and highly acculturated Hispanics of Mexican descent characteristics.

\begin{tabular}{|c|c|c|c|}
\hline \multirow[b]{3}{*}{ n } & \multicolumn{2}{|c|}{$\begin{array}{c}\text { Least } \\
\text { Highly } \\
\text { acculturated acculturated }\end{array}$} & \multirow[b]{3}{*}{$p$} \\
\hline & HMD $^{\mathrm{a}}$ & HMD $^{\mathrm{a}}$ & \\
\hline & 898 & 541 & \\
\hline Gender ( $\%$ Male/Female $)$ & $39.5 / 60.5$ & $47.3 / 52.7$ & \\
\hline Age (years, mean \pm SD) & $42.6 \pm 15.8$ & $39.6 \pm 15.6$ & $<0.001$ \\
\hline $\mathrm{BMI}^{\mathrm{b}}\left(\mathrm{kg} / \mathrm{m}^{2}\right.$, mean $\left.\pm \mathrm{SD}\right)$ & $28.1 \pm 6.8$ & $28.1 \pm 6.0$ & 0.977 \\
\hline Smokers $(\%)$ & 13.8 & 17.4 & 0.068 \\
\hline Alcohol consumers $(\%)$ & 25.7 & 45.3 & $<0.001$ \\
\hline Caffeine consumers $(\%)$ & 69.3 & 56 & $<0.001$ \\
\hline Sleep disorder treatment (\%) & 8.8 & 8.5 & 0.920 \\
\hline Depression/ anxiety diagnosis (\%) & 27.8 & 27 & 0.692 \\
\hline Poor sleep quality $\left(\mathrm{PSQI}^{\mathrm{c}}>5\right)$ & 62.6 & 67.2 & 0.077 \\
\hline
\end{tabular}

${ }^{\mathrm{a}} \mathrm{HMD}=$ Hispanics of Mexican descent; ${ }^{\mathrm{b}} \mathrm{BMI}=$ Body mass index; ${ }^{\mathrm{c}} \mathrm{Pitts}-$ burgh Sleep Quality Index.

acculturated, compared with the least acculturated was not significantly different $(67.2 \%$ vs. $62.6 \%, p=0.077)$, Table 2. Assessment of PSQI individual components (subjective sleep quality, sleep latency, sleep duration, habitual sleep efficiency, sleep disturbance, use of sleeping medication and daytime dysfunction) showed significant differences between both ethnic groups only in the use of sleeping medication and habitual sleep efficiency. HMD were less likely to use sleep medication than NHW $(17.2 \%$ vs. $28.8 \%, p<0.001)$, and reported significantly lower sleep efficiency $(83.8 \% \pm 14.7$ vs. $85.6 \% \pm 13.6, p=0.001)$.

\subsection{Predictors of Sleep Quality}

We performed logistic regression analysis to determine risk factors for poor sleep quality in the overall sample and for HMD and NHW separately. When the entire population was included, ethnicity was not a risk factor 
Table 3. Pittsburgh sleep quality index sub-scale scores for Hispanics of Mexican descent and Non-Hispanic Whites (Mean \pm SD).

\begin{tabular}{lccc}
\hline & HMD $^{\mathbf{a}}$ & NHW $^{\mathbf{b}}$ & \\
\hline $\mathbf{n}$ & $\mathbf{1 4 4 5}$ & $\mathbf{1 6 9 3}$ & $p$ \\
\hline PSQI & & & \\
\hline $\begin{array}{l}\text { PSQI 1: Subjective sleep } \\
\text { quality }\end{array}$ & $1.03 \pm 0.82$ & $0.99 \pm 0.81$ & 0.176 \\
PSQI 2: Sleep latency & $1.14 \pm 0.95$ & $1.09 \pm 0.97$ & 0.102 \\
PSQI 3: Sleep duration & $1.02 \pm 1.08$ & $1.13 \pm 1.19$ & 0.075 \\
PSQI 4: Sleep efficiency & $0.74 \pm 0.99$ & $0.63 \pm 0.97$ & 0.001 \\
PSQI 5: Sleep disturbances & $1.25 \pm 0.68$ & $1.26 \pm 0.60$ & 0.613 \\
PSQI 6: Sleep medication use & $0.39 \pm 0.92$ & $0.67 \pm 1.14$ & $<0.001$ \\
PSQI 7: Daytime dysfunction & $0.89 \pm 0.92$ & $0.89 \pm 0.81$ & 0.934 \\
Sleep efficiency (\%) & $83.80 \pm 14.68$ & $85.56 \pm 13.63$ & 0.003 \\
$\begin{array}{l}\text { Poor sleep quality } \\
\text { (PSQI > 5, \%) }\end{array}$ & 64.4 & 64.3 & 0.933 \\
$\begin{array}{l}\text { Poor sleep quality } \\
\text { (PSQI > 5, \%) (M/F }\end{array}$ & $59.9 / 67.7$ & $61.6 / 66.9$ & $0.012 /$ \\
PSQI global index & $6.65 \pm 4.10$ & $6.67 \pm 4.06$ & 0.904 \\
\hline
\end{tabular}

${ }^{a}$ Hispanics of Mexican descent; ${ }^{b}$ Non-Hispanic Whites; ${ }^{\text {cPittsburgh Sleep }}$ Quality Index; ${ }^{\mathrm{d}}$ Male/Female.

for sleep quality after controlling for age, gender, BMI, smoking, use of alcoholic or caffeinated beverages, reported presence of sleep disorders or reported diagnosis of anxiety or depression. Table 4 shows the predictors of poor sleep quality for HMD. In HMD, a reported diagnosis of depression or anxiety (OR $3.444,95 \%$ CI 2.512 , $4.722, p<0.001)$ and being female (OR 1.388, 95\% CI $1.091,1.766, p=0.008)$ were independent predictors of poor sleep quality. Acculturation to the US lifestyle was not a predictor of poor sleep quality. Highly acculturated young HMD males had a significantly higher prevalence of poor sleep quality $(64.8 \%$ vs. $49.8 \% p<0.001)$ after Bonferroni correction, than older HMD males, or women regardless of acculturation status (Figure 1). Table 5 shows the predictors of poor sleep quality for NHW. In NHW, the report of a diagnosis of depression or anxiety was the strongest independent risk factor for poor sleep quality (OR 2.699, 95\% CI 2.093, 3.481, $p<0.001$ ). In addition, being female (OR 1.26, 95\% CI 1.015, 1.564, $p$ $=0.036)$ and smoking (OR 1.656, 95\% CI 1.240, 2.212, $p$ $=0.001)$ were independent predictors and age and BMI were weak but statistically significant predictors of poor sleep quality.

\section{Discussion}

The present study examined subjective sleep quality in a large sample of US HMD living in San Diego County (California, US) and compared them to NHW. We demonstrated that that poor sleep quality is highly prevalent in

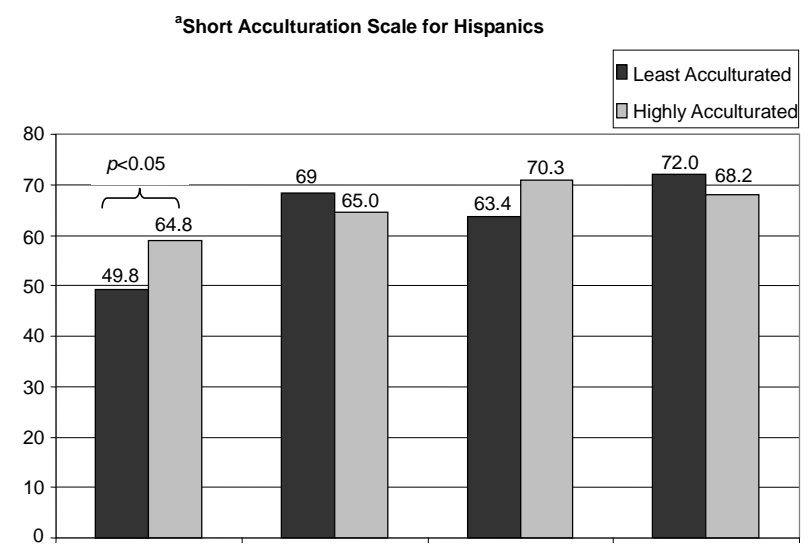

Figure 1. Sleep quality and acculturation by age and gender in Hispanics of Mexican-descent. The results show no differences among less and highly acculturated women. However, young highly acculturated men had significantly poorest sleep quality compared with least acculturated young men adults $(p<0.001)$.

HMD and NHW living in San Diego County, CA, but not significantly different between these ethnic groups. We found that the strongest predictor of poor sleep quality was the prior diagnosis of depression or anxiety. In addition, our data suggest that the level of acculturation to the US lifestyle could play a significant role in determining an impaired sleep quality among young HMD men.

Previous research in general population has shown a great variability in the prevalence of poor sleep quality, [30-32] however; it is not clear yet what causes these heterogenic results. For example, Buysse et al. found poor sleep quality on the PSQI in $50.8 \%$ of 187 adults in a US community sample where $41.2 \%$ were AfricanAmericans, [31,32] while Ramsawh and collaborators found poor sleep quality in 35\% of 4181 German subjects using the PSQI as well [31,32]. In our large sample, we found an even higher prevalence of poor sleep quality among subjects. For instance, sleep complaints and prevalence of poor sleep quality may be affected by the measuring instrument, race/ethnic, age, and gender proportions, health status, socioeconomic and cultural makeup of the study population, all of which may explain the differences among studies published comparing ethnic groups $[30,32,33]$. In the recent Sleep America Poll 2010, which focused on ethnicity, the reported prevalence of sleeping poorly at least one day a week was $60 \%$ regardless of ethnicity, results comparable to our findings [34]. It is important to notice, that there have been very few researches exploring thoroughly sleep disturbances among different ethnic groups and furthermore, studies among Hispanics are almost nonexistent. With few exceptions, US Hispanics are only a small proportion of epidemiologic studies, although it is the second largest ethnic group in the United States [16]. In a study evalu- 
Table 4. Risk factors of poor sleep quality (Pittsburgh sleep quality index global index > 5) for Hispanics of Mexican descent $(\mathbf{n}=1386)$.

\begin{tabular}{|c|c|c|c|c|c|c|c|c|}
\hline \multirow{2}{*}{ Variables in the equation } & \multirow[b]{2}{*}{ B } & \multirow[b]{2}{*}{$\mathrm{SE}$} & \multirow[b]{2}{*}{ Wald } & \multirow[b]{2}{*}{ df } & \multirow[b]{2}{*}{ Sig. } & \multirow[b]{2}{*}{$\operatorname{Exp}(B)$} & \multicolumn{2}{|c|}{$95 \%$ CI for $\operatorname{Exp}(B)$} \\
\hline & & & & & & & Lower & Upper \\
\hline Depression/ anxiety & 1.237 & 0.161 & 58.994 & 1 & $<0.001$ & 3.444 & 2.512 & 4.722 \\
\hline Sleep disorder & 0.388 & 0.269 & 2.084 & 1 & 0.149 & 1.474 & 0.870 & 2.496 \\
\hline Gender & 0.328 & 0.123 & 7.130 & 1 & 0.008 & 1.388 & 1.091 & 1.766 \\
\hline Alcohol & 0.255 & 0.132 & 3.739 & 1 & 0.053 & 1.290 & 0.997 & 1.670 \\
\hline Smoking & 0.214 & 0.169 & 1.599 & 1 & 0.206 & 1.239 & 0.889 & 1.726 \\
\hline Acculturation & 0.184 & 0.124 & 2.205 & 1 & 0.138 & 1.202 & 0.943 & 1.534 \\
\hline BMI & 0.004 & 0.010 & 0.211 & 1 & 0.646 & 1.004 & 0.986 & 1.023 \\
\hline Age & 0.003 & 0.004 & 0.429 & 1 & 0.512 & 1.003 & 0.995 & 1.010 \\
\hline Caffeine & -0.208 & 0.127 & 2.684 & 1 & 0.101 & 0.812 & 0.634 & 1.042 \\
\hline
\end{tabular}

Note: Acculturation = level of acculturation to the US lifestyle; Alcohol = reported use of alcoholic beverages; BMI = body mass index; Caffeine = reported use of caffeinated beverages; Depression/Anxiety = prior diagnosis of depression and/or anxiety; Sleep Disorder = prior treatment for a sleep disorder.

Table 5. Risk factors of poor sleep quality (Pittsburgh sleep quality index global score $>5)$ for non-Hispanic Whites $(n=$ 1675).

\begin{tabular}{|c|c|c|c|c|c|c|c|c|}
\hline \multirow{2}{*}{ Variables in the equation } & \multirow[b]{2}{*}{ B } & \multirow[b]{2}{*}{ SE } & \multirow[b]{2}{*}{ Wald } & \multirow[b]{2}{*}{ df } & \multirow[b]{2}{*}{ Sig. } & \multirow[b]{2}{*}{$\operatorname{Exp}(B)$} & \multicolumn{2}{|c|}{$95 \%$ CI for $\operatorname{Exp}(B)$} \\
\hline & & & & & & & Lower & Upper \\
\hline Depression/ anxiety & 0.993 & 0.130 & 58.503 & 1 & $<0.001$ & 2.699 & 2.093 & 3.481 \\
\hline Smoking & 0.505 & 0.148 & 11.691 & 1 & 0.001 & 1.656 & 1.240 & 2.212 \\
\hline Sleep disorder & 0.321 & 0.167 & 3.686 & 1 & 0.055 & 1.378 & 0.993 & 1.911 \\
\hline Gender & 0.231 & 0.110 & 4.380 & 1 & 0.036 & 1.260 & 1.015 & 1.564 \\
\hline BMI & 0.029 & 0.010 & 8.182 & 1 & 0.004 & 1.029 & 1.009 & 1.050 \\
\hline Alcohol & 0.014 & 0.110 & 0.016 & 1 & 0.899 & 1.014 & 0.817 & 1.259 \\
\hline Age & -0.006 & 0.003 & 3.874 & 1 & 0.049 & 0.994 & 0.988 & 1.000 \\
\hline Caffeine & -0.140 & 0.115 & 1.476 & 1 & 0.224 & 0.869 & 0.694 & 1.090 \\
\hline Constant & -0.279 & 0.352 & 0.629 & 1 & 0.428 & 0.756 & & \\
\hline
\end{tabular}

Note: Alcohol $=$ reported use of alcoholic beverages; BMI = body mass index; Caffeine $=$ reported use of caffeinated beverages; Depression/Anxiety = prior diagnosis of depression and/or anxiety; Sleep Disorder = prior treatment for a sleep disorder.

ating sleep complaints in 88,062 people from the US Behavioral Risk Factor Surveillance System survey $(4.7 \%$ Hispanics), Chowdhury et al. found that African-Americans, Hispanics and Asians were less likely to report sleep complaints compared to Caucasians [35]. Grandner et al. did a similar study with 159,856 subjects $(17.4 \%$ Hispanics) and found that African-American and Hispanic women and Asian men had less sleep complaints than NHW women and men respectively [36]. We did not find significant differences between HMD and NHW in their global sleep quality or in their reported sleep latency, sleep duration, daytime dysfunction and sleep disturbances as measured by the PSQI. However, a few differences were noted: NHW reported greater use of sleep medications compared to HMD, which conforms to previous reports $[37,38]$. Potential reasons have been advanced including racial/ethnic differences in the percep- tion of illness, safety and efficacy of medications, and reduced access to physicians and prescription medications among minorities [39]. Another difference found in our study was that HMD also reported significantly lower sleep efficiency. The sleep efficiency of NHW was $85.6 \%$ (normal $\geq 85 \%$ ), while that of HMD was significantly lower and below the clinical level of normality at $83.8 \%$. Our findings differ from the sleep efficiency observed among various ethnic groups including Whites and Hispanics reported by Redline and collaborators [40]. Redline's study showed no ethnic differences in sleep efficiency using polysomnography. The PSQI provides an average of the assessment of sleep quality over the past month while the subjects sleep in their natural environment; the polysomnogram, however, is based on one overnight study that by its nature changes and standardizes the subjects' usual sleep conditions thus potentially 
explaining the finding of no ethnic difference in sleep efficiency. We did not evaluate the effect of sleep environment on sleep quality in this study, but the sleep environment may be an important determinant of sleep quality as noted by the Ruiter et al.'s meta-analysis where African Americans had worse sleep continuity and duration when sleeping at home than in the sleep laboratory [41]. According to the 2003 National Institute of Health National Sleep Disorders Research Plan, racial and ethnic minorities, and those who are socioeconomically disadvantaged are more likely to sleep in less than optimal environments (e.g., too hot or too cold, noisy, or crowded) and may explain our findings [42].

We evaluated potential risk factors for poor sleep quality by multivariate analyses in HMD and NHW. A prior diagnosis of depression or anxiety was a strong risk factor for poor sleep quality in both ethnic groups. In previous work studying predictors of insomnia in breast cancer survivors, we found that of 27 potential risk factors, only depression and vasomotor symptoms were significant [43]. Our results are also in agreement with multiple reports that found a correlation of poor sleep quality with several factors such mood impairment, anxiety, being female and ethnic groups including NHW, African-American, German, and Chinese populations [30-32]. [44-47] Buysse et al. reported that being a woman, higher scores in perceived stress, anxiety, anger, hostility and pessimism were also risk factors for poor sleep quality [32]. Ramsawh et al. reported also that being a woman and anxiety were risk factors for poor sleep quality [31]. Baker et al. found that poor sleep quality was associated with lifestyle, health status, and socio-demographic factors [30]. In our current study, the use of alcoholic beverages approached significance (OR $1.29, p=0.05$ ) as a predictor of poor sleep quality only in HMD. Recently, Ehlers et al., evaluated a group of young Hispanic men (ages 18 to 30) in San Diego County and reported that life time diagnosis of alcoholuse disorder, family history of alcohol dependence, acculturation stress, and lifetime diagnoses of major depressive disorder were all correlated with significantly poorer sleep quality as measured by the global score on the PSQI, [48] which appears to agree with our finding. Similar to our findings, some published datashow that women more frequently report poor sleep quality [49-51]. We found that both HMD and NHW women had higher prevalence of poor sleep quality as compared to men, and significantly higher mean PSQI global score. Hall et al. evaluated 370 NHW, African-American, and Chinese women and found that $66 \%$ of participants reported poor sleep quality, with African-American women reporting more complaints about sleep measured with the PSQI, similar results to current study [52]. On his study, Hall studied middle-aged women who may had been affected by physiological changes, such as menopause, which may have a high impact on sleep quality [53] and also sleep complaints that may increase with aging [54].

Studies of Hispanic immigrants and their descendants have documented higher rates of obesity [55-58], diabetes $[55,59,60]$, cardiovascular disease [60-63], and psychiatric disorders $[65,66]$ with increasing acculturation to the US lifestyle. Little is known of the effects of acculturation on sleep and sleep quality. A study of middleaged and elderly Hispanic women examined sleeping habits among other health habits and found that acculturation negatively affected the sleep habits of middle-aged but not elderly Hispanic women [67]. A study of adolescent Hispanic men (ages 11 - 19), suggested that higher levels of acculturation were associated with an increased likelihood of fewer hours of sleep per night, among other deleterious health behaviors [68]. In the current study, in the overall sample analysis, acculturation to the US lifestyle was not a significant predictor of sleep quality on multivariate analyses, suggesting that acculturation may be only one of many factors in the sleep quality of Hispanics living in the US [69,70]. Our findings are similar to those of Roberts et al. who found that ninth-grade-Hispanic students who identified themselves as Mexican-Americans rather than Mexican were at a higher risk for poor sleep quality as denoted by insomnia. However, it is an interesting observation that in the current study, on post hoc analyses, highly acculturated young HMD males had a significantly greater prevalence of poor sleep quality when compared to their least acculturated counterparts. Results consistent with reports from Cantero [67] and Ebin [68] suggesting that younger Latinos may be more susceptible to negative health outcomes of acculturation including poor sleep quality. Potential causes for acculturation-associated poor sleep quality include reduced hours of sleep, irregular sleep schedules, increased use of alcohol, tobacco, and stimulants, and the social stress needed to keep up with the busy American lifestyle [55,65,71-83].

\subsection{Limitations}

We endeavored to obtain the most representative sample population of HMD and NHW in San Diego County by using random digit dialing and randomization of qualifying household adult members, which greatly increases confidence in the applicability of our findings. We also utilized professional culturally competent interviewers to conduct the study in the subject's language of choice. However, only land lines were called. That can introduce a selection bias as many people don't use land lines anymore, or even sometimes, they may not answer incoming calls. It is unknown the impact to the study, furthermore perhaps more stay-home subjects responded the land line phone leading to a misrepresented cultural or 
economic populations. Of the 3667 subjects who took the call and agreed to participate, all completed the survey. However, the sample population had to be reduced significantly, potentially reducing power, due to exclusion of cases where the subject reported logically inconsistent information about their sleep. Another limitation was the cross-sectional nature of the study, which did not allow us to make causal associations. Measurement of sleep quality using the PSQI, although subjective, may have an advantage over objective measurements of sleep quality such as polysomnography or actigraphy, since it represents the subjects experience over the last 30 days rather than the sleep quality over one night or a few nights. Quality of sleep can be influenced by many other potential factors that due to time constraints and subject burden were not evaluated in the study.

\subsection{Conclusion}

Poor sleep quality was common and equally prevalent between HMD and NHW in a large sample of subjects living in San Diego County. Having been diagnosed of depression and/or anxiety and being a woman were strong predictors of poor sleep quality in both ethnic groups. Post hoc analyses suggested that sleep quality of young male HMD might be more susceptible to the deleterious effects of acculturation to the US lifestyle. Further research is warranted to better understand the high prevalence of poor sleep quality among this large population and to study the role of acculturation in young HMD subjects and its certain negative health effect.

\section{Key Findings}

- Hispanics of Mexican descent and non-Hispanic Whites living in San Diego, CA, had a highly prevalent poor sleep quality.

- Ethnicity was not a predictor of poor sleep quality on those two racial groups.

- A prior diagnosis of depression or anxiety was the best predictor of poor sleep quality regardless the ethnic group.

- An elevated acculturation to the US lifestyle has a negative impact on sleep health in young Hispanics of Mexican descent males.

\section{Acknowledgements}

This study was supported by NIH-HL075630 grant (JSL and XS); by AG08415 grant (SAI); and by Spanish Ministry of Education AP 2007-02965 fellowship grant (CDP).

\section{REFERENCES}

[1] M. Vandekerckhove and R. Cluydts, "The Emotional Brain and Sleep: An Intimate Relationship," Sleep Medi- cine Reviews, Vol. 14, No. 4, 2010, pp. 219-226. doi:10.1016/j.smrv.2010.01.002

[2] M. D. Althuis, L. Fredman, P. W. Langenberg and J. Magaziner, "The Relationship between Insomnia and Mortality among Community-Dwelling Older Women," Journal of the American Geriatrics Society, Vol. 46, No. 10, 1998, pp. 1270-1273.

[3] D. F. Kripke, S. Ancoli-Israel, M. R. Klauber, D. L. Wingard, W. J. Mason and D. J. Mullaney, "Prevalence of Sleep-Disordered Breathing in Ages 40 - 64 Years: A Population-Based Survey," Sleep, Vol. 20, No. 1, 1997, pp. 65-76.

[4] J. W. Shepard, Jr., "Hypertension, Cardiac Arrhythmias, Myocardial Infarction, and Stroke in Relation to Obstructive Sleep Apnea," Clinics in Chest Medicine, Vol. 13, No. 3, 1992, pp. 437-458.

[5] H. Schafer, U. Koehler, S. Ewig, E. Hasper, S. Tasci and B. Luderitz, "Obstructive Sleep Apnea as a Risk Marker in Coronary Artery Disease," Cardiology, Vol. 92, No. 2, 1999, pp. 79-84. doi:10.1159/000006952

[6] L. J. Findley, M. Fabrizio, G. Thommi and P. M. Suratt, "Severity of Sleep Apnea and Automobile Crashes," New England Journal of Medicine, Vol. 320, No. 13, 1989, pp. 868-869. doi:10.1056/NEJM198903303201314

[7] T. Young, M. Palta, J. Dempsey, J. Skatrud, S. Weber and S. Badr, "The Occurrence of Sleep-Disordered Breathing among Middle-Aged Adults," England Journal of Medicine, Vol. 328, No. 17, 1993, pp. 1230-1235. doi:10.1056/NEJM199304293281704

[8] S. D. Youngstedt, P. J. O'Connor and R. K. Dishman, "The Effects of Acute Exercise on Sleep: A Quantitative Synthesis," Sleep, Vol. 20, No. 3, 1997, pp. 203-214.

[9] G. Jean-Louis, C. Magai, G. J. Casimir, F. Zizi, F. Moise, D. McKenzie, et al., "Insomnia Symptoms in a Multiethnic Sample of American Women," Journal of Women's Health, Vol. 17, No. 1, 2008, pp. 15-25. doi:10.1089/jwh.2006.0310

[10] J. Profant, S. Ancoli-Israel and J. E. Dimsdale, "Are There Ethnic Differences in Sleep Architecture?" American Journal of Human Biology, Vol. 14, No. 3, 2002, pp. 321-326. doi:10.1002/ajhb.10032

[11] U. Rao, C. L. Hammen and R. E. Poland, "Ethnic Differences in Electroencephalographic Sleep Patterns in Adolescents," Asian Journal of Psychiatry, Vol. 2, No. 1, 2009, pp. 17-24. doi:10.1016/j.ajp.2008.12.003

[12] M. E. Ruiter, J. DeCoster, L. Jacobs and K. L. Lichstein, "Sleep Disorders in African Americans and Caucasian Americans: A Meta-Analysis," Behavioral Sleep Medicine, No. 4, 2010, pp. 246-259. doi:10.1080/15402002.2010.509251

[13] C. J. Stepnowsky Jr., P. J. Moore and J. E. Dimsdale, "Effect of Ethnicity on Sleep: Complexities for Epidemiologic Research," Sleep, Vol. 26, No. 3, 2003, pp. 329332.

[14] S. F. Quan, J. L. Goodwin, S. I. Babar, K. L. Kaemingk, P. L. Enright, G. M. Rosen, et al., "Sleep Architecture in normal Caucasian and Hispanic Children Aged 6-11 Years Recorded during Unattended Home Polysomno- 
graphy: Experience from the Tucson Children's Assessment of Sleep Apnea Study (TuCASA)," Sleep Medicine, Vol. 4, No. 1, 2003, pp. 13-19. doi:10.1016/s1389-9457(02)00235-6

[15] P. R. Castillo, J. Kaplan, S. C. Lin, P. A. Fredrickson and M. W. Mahowald, "Prevalence of Restless Legs Syndrome among Native South Americans Residing in Coastal and Mountainous Areas," Mayo Clinic Proceedings, Vol. 81, No. 10, 2006, pp. 1345-1347. doi:10.4065/81.10.1345

[16] S. Shafazand, D. M. Wallace, S. S. Vargas, Y. Del Toro, S. Dib, A. R. Abreu, et al., "Sleep Disordered Breathing, Insomnia Symptoms, and Sleep Quality in a Clinical Cohort of US Hispanics in South Florida," Journal of Clinical Sleep Medicine, Vol. 8, No. 5, 2012, pp. 507-514.

[17] S. Subramanian, B. Guntupalli, T. Murugan, S. Bopparaju, S. Chanamolu, L. Casturi, et al., "Gender and Ethnic Differences in Prevalence of Self-Reported Insomnia among patients with Obstructive Sleep Apnea," Sleep \& Breathing, Vol. 15, No. 4, 2011, pp. 711-715. doi:10.1007/s11325-010-0426-4

[18] L. Tomfohr, M. A. Pung, K. M. Edwards and J. E. Dimsdale, "Racial Differences in Sleep Architecture: The Role of Ethnic Discrimination," Biological Psychology, Vol. 89 , No. 1, 2012, pp. 34-38. doi:10.1016/j.biopsycho.2011.09.002

[19] Y. Song, X. Zhang, J. Ma, B. Zhang, P. J. Hu and B. Dong, "Behavioral Risk Factors for Overweight and Obesity among Chinese Primary and Middle School Students in 2010," Chinese Journal of Preventive Medicine, Vol. 46, No. 9, 2012, pp. 789-795.

[20] K. Ladenheim, "Collecting from the Uninsured: Hospital Billing Practices," NCSL Legisbrief, Vol. 14, No. 34, 2006, pp. 1-2.

[21] B. Guzman and E. D. McConnell, "The Hispanic population: 1990-2000 Growth and Change," Population Research and Policy Review, Vol. 21, No. 1-2, 2002, pp. 109128. doi:10.1023/A:1016541906218

[22] L. E. Skolarus, L. D. Lisabeth, L. B. Morgenstern, W. Burgin and D. L. Brown, "Sleep Apnea Risk among Mexican American and Non-Hispanic White Stroke Survivors," A Journal of Cerebral Circulation, Vol. 43, No. 4, 2012, pp. 1143-1145.

[23] M. R. Benjamins, J. Hirschman, J. Hirschtick and S. Whitman, "Exploring Differences in Self-Rated Health among Blacks, Whites, Mexicans, and Puerto Ricans," Ethnicity \& Health, Vol. 17, No. 5, 2012, pp. 463-476. doi:10.1080/13557858.2012.654769

[24] J. Waksberg, "Sampling Methods for Random Digit Dialing," Journal of the American Statistical Association, Vol. 73, No. 361, 1978, pp. 40-46. doi:10.1080/01621459.1978.10479995

[25] G. Marin, F. Sabogal, B. V. Marin, R. Otero-Sabogal and E. J. Perez-Stable, "Development of a Short Acculturation Scale for Hispanics," Hispanic Journal of Behavioral Sciences, Vol. 9, No. 2, 1987, pp. 183-205. doi: $10.1177 / 07399863870092005$

[26] D. J. Buysse, C. F. Reynolds, 3rd, T. H. Monk, S. R. Berman and D. J. Kupfer, "The Pittsburgh Sleep Quality Index: A New Instrument for Psychiatric Practice and
Research," Psychiatry Research, Vol. 28, No. 2, 1989,pp. 193-213. doi:10.1016/0165-1781(89)90047-4

[27] A. M. J. Royuela, "Propiedades Clinimétricas de la Versión Castellana del Cuestionario de Pittsburgh," Vigilia-Sueño, No. 9, 1997, pp. 81-94.

[28] F. Escobar-Cordoba and J. Eslava-Schmalbach, "Colombian validation of the Pittsburgh Sleep Quality Index," Revista de Neurologia, Vol. 40, No. 3, 2005, pp. 150-155.

[29] A. Jimenez-Genchi, E. Monteverde-Maldonado, A. Nenclares-Portocarrero, G. Esquivel-Adame and A. de la Vega-Pacheco, "Reliability and Factorial Analysis of the Spanish Version of the Pittsburg Sleep Quality Index among Psychiatric Patients," Gaceta medica de Mexico, Vol. 144, No. 6, 2008, pp. 491-496.

[30] F. C. Baker, A. R. Wolfson and K. A. Lee, "Association of Sociodemographic, Lifestyle, and Health Factors with Sleep Quality and Daytime Sleepiness in Women: Findings from the 2007 National Sleep Foundation 'Sleep in America Poll',' Journal of Women's Health (Larchmt), Vol. 18, No. 6, 2009, pp. 841-849. doi:10.1089/jwh.2008.0986

[31] H. J. Ramsawh, M. B. Stein, S. L. Belik, F. Jacobi and J. Sareen, "Relationship of Anxiety Disorders, Sleep Quality, and Functional Impairment in a Community Sample," Journal of Psychiatric Research, Vol. 43, No. 10, 2009, pp. 926-933. doi:10.1016/j.jpsychires.2009.01.009

[32] D. J. Buysse, M. L. Hall, P. J. Strollo, T. W. Kamarck, J. Owens, L. Lee, et al., "Relationships between the Pittsburgh Sleep Quality Index (PSQI), Epworth Sleepiness Scale (ESS), and Clinical/Polysomnographic Measures in a Community Sample," Journal of Clinical Sleep Medicine, Vol. 4, No. 6, 2008, pp. 563-571.

[33] E. J. Mezick, K. A. Matthews, M. Hall, P. J. Strollo, Jr., D. J. Buysse, T. W. Kamarck, et al., "Influence of Race and Socioeconomic Status on Sleep: Pittsburgh Sleep SCORE Project," Psychosomatic Medicine, Vol. 70 No. 4, 2008, pp. 410-416. doi:10.1097/PSY.0b013e31816fdf21

[34] National Sleep Foundation, "2010 Sleep in America Poll." http://www.sleepfoundation.org/article/sleep-america-poll s/2010-sleep-and-ethnicity

[35] P. P. Chowdhury, L. Balluz and T. W. Strine, "HealthRelated Quality of Life among Minority Populations in the United States, BRFSS 2001-2002," Ethnicity \& Disease, Vol. 18, No. 4, 2008, pp. 483-487.

[36] M. A. Grandner, N. P. Patel, P. R. Gehrman, D. Xie, D. Sha, T. Weaver, et al., "Who Gets the Best Sleep? Ethnic and Socioeconomic Factors Related to Sleep Complaints," Sleep Medicine, Vol. 11, No. 5, 2010, pp. 470-478. doi:10.1016/j.sleep.2009.10.006

[37] S. Ram, H. Seirawan, S. K. Kumar and G. T. Clark, "Prevalence and Impact of Sleep Disorders and Sleep Habits in the United States," Sleep \& Breathing, Vol. 14, No. 1, 2010, pp. 63-70. doi:10.1007/s11325-009-0281-3

[38] E. P. Cherniack, J. Ceron-Fuentes, H. Florez, L. Sandals, O. Rodriguez and J. C. Palacios, "Influence of Race and Ethnicity on Alternative Medicine as a Self-Treatment Preference for Common Medical Conditions in a Population of Multi-Ethnic Urban Elderly," Complementary Therapies in Clinical Practice, Vol. 14, No. 2, 2008, pp. 
116-123. doi:10.1016/j.ctcp.2007.11.002

[39] M. A. Clark, M. L. Rogers and S. M. Allen, "Conducting Telephone Interviews with Community-Dwelling Older Adults in a State Medicaid Program: Differences by Ethnicity and Language Preference," Journal of Health Care for the Poor and Underserved, Vol. 21, No. 4, 2010, pp. 1304-1317.

[40] S. Redline, H. L. Kirchner, S. F. Quan, D. J. Gottlieb, V. Kapur and A. Newman, "The Effects of Age, Sex, Ethnicity, and Sleep-Disordered Breathing on Sleep Architecture," Archives of Internal Medicine, Vol. 164, No. 4, 2004, pp. 406-418. doi:10.1001/archinte.164.4.406

[41] M. E. Ruiter, J. Decoster, L. Jacobs and K. L. Lichstein, "Normal Sleep in African-Americans and CaucasianAmericans: A Meta-Analysis," Sleep Medicine, Vol. 12, No. 3, 2011, pp. 209-214. doi:10.1016/j.sleep.2010.12.010

[42] "2003 National Sleep Disorders Research Plan," Sleep, Vol. 26, No. 3, 2003, pp. 253-257.

[43] W. A. Bardwell, J. Profant, D. R. Casden, J. E. Dimsdale, S. Ancoli-Israel, L. Natarajan, C. L. Rock, J. P. Pierce, and Women's Healthy Eating \& Living (WHEL) Study Group, "The Relative Importance of Specific Risk Factors for Insomnia in Women Treated for Early-Stage Breast Cancer," Psychooncology, Vol. 17, No. 1, 2008, pp. 9-18.

[44] M. M. Ohayon, "Epidemiology of Insomnia: What We Know and What We Still Need to Learn," Sleep Medicine Reviews, Vol. 6, No. 2, 2002, pp. 97-111. doi:10.1053/smrv.2002.0186

[45] O. Dogan, S. Ertekin and S. Dogan, "Sleep Quality in Hospitalized Patients," Journal of Clinical Nursing, Vol. 14, No. 1, 2005, pp. 107-113. doi:10.1111/j.1365-2702.2004.01011.x

[46] J. F. Owens and K. A. Matthews, "Sleep Disturbance in Healthy Middle-Aged Women," Maturitas, Vol. 30, No. 1, 1998, pp. 41-50. doi:10.1016/S0378-5122(98)00039-5

[47] A. G. Wheaton, G. S. Perry, D. P. Chapman and J. B. Croft, "Sleep Disordered Breathing and Depression among US Adults: National Health and Nutrition Examination Survey, 2005-2008," Sleep, Vol. 35, No. 4, 2012, pp. 461-467.

[48] C. L. Ehlers, D. A. Gilder, J. R. Criado and R. Caetano, "Sleep Quality and Alcohol-Use Disorders in a Select Population of Young-Adult Mexican Americans," Journal of Studies on Alcohol and Drugs, Vol. 71, No. 6, 2010, pp. 879-884.

[49] A. Dzaja, S. Arber, J. Hislop, M. Kerkhofs, C. Kopp, T. Pollmacher, et al., "Women's Sleep in Health and Disease," Journal of Psychiatric Research, Vol. 39, No. 1, 2005, pp. 55-76. doi:10.1016/j.jpsychires.2004.05.008

[50] M. L. Unruh and S. Redline, M. W. An, D. J. Buysse, F. J. Nieto, J. L. Yeh, et al., "Subjective and Objective Sleep Quality and Aging in the Sleep Heart Health Study," Journal of the American Geriatrics Society, Vol. 56, No. 7, 2008, pp. 1218-1227. doi:10.1111/j.1532-5415.2008.01755.x

[51] B. Zhang and Y. K. Wing, "Sex Differences in Insomnia: A Meta-Analysis," Sleep, Vol. 29, No. 1, 2006, pp. 85-93.
[52] M. H. Hall, K. A. Matthews, H. M. Kravitz, E. B. Gold, D. J. Buysse, J. T. Bromberger, et al., "Race and Financial Strain Are Independent Correlates of Sleep in Midlife Women: The SWAN Sleep Study," Sleep, Vol. 32, No. 1, 2009, pp. 73-82.

[53] H. Hachul, M. L. Andersen, L. R. A. Bittencourt, R. Santos-Silva, S. G. Conway and S. Tufik, "Does the Reproductive Cycle Influence Sleep Patterns in Women with Sleep Complaints?" Climacteric, Vol. 13, No. 6, 2010, pp. 594-603. doi:10.3109/13697130903450147

[54] M. M. Ohayon, M. A. Carskadon, C. Guilleminault and M. V. Vitiello, "Meta-Analysis of Quantitative Sleep Parameters from Childhood to Old Age in Healthy Individuals: Developing Normative Sleep Values across the Human Lifespan," Sleep, Vol. 27, No. 7, 2004, pp. 12551273.

[55] H. P. Hazuda, S. M. Haffner, M. P. Stern and C. W. Eifler, "Effects of Acculturation and Socioeconomic Status on Obesity and Diabetes in Mexican Americans. The San Antonio Heart Study," American Journal of Epidemiology, Vol. 128, No. 6, 1988, pp. 1289-1301.

[56] I. G. Pawson, R. Martorell and F. E. Mendozam, "Prevalence of Overweight and Obesity in US Hispanic Populations," The American Journal of Clinical Nutrition, Vol. 53, Suppl. 6, 1991, pp. 1522S-1528S.

[57] L. K. Khan, J. Sobal and R. Martorell, "Acculturation, Socioeconomic Status, and Obesity in Mexican Americans, Cuban Americans, and Puerto Ricans," International Journal of Obesity and Related Metabolic Disorders, Vol. 21, No. 2, 1997, pp. 91-96. doi:10.1038/sj.ijo.0800367

[58] J. Sundquist and M. Winkleby, "Country of Birth, Acculturation Status and Abdominal Obesity in a National Sample of Mexican-American Women and Men," International Journal of Epidemiology, Vol. 29, No. 3, 2000, pp. 470-477. doi:10.1093/ije/29.3.470

[59] J. M. Samet, D. B. Coultas, C. A. Howard, B. J. Skipper and C. L. Hanis, "Diabetes, Gallbladder Disease, Obesity, and Hypertension among Hispanics in New Mexico," American Journal of Epidemiology, Vol. 128, No. 6, 1988, pp. 1302-1311.

[60] M. P. Stern, J. A. Knapp, H. P. Hazuda, S. M. Haffner, J. K. Patterson and B. D. Mitchell, "Genetic and Environmental Determinants of Type II Diabetes in Mexican Americans. Is There a 'Descending Limb' to the Modernization/Diabetes Relationship?" Diabetes Care, Vol. 14, No. 7, 1991, pp. 649-654. doi:10.2337/diacare.14.7.649

[61] J. Sundquist and M. A. Winkleby, "Cardiovascular Risk Factors in Mexican American Adults: A Transcultural Analysis of NHANES III, 1988-1994," American Journal of Public Health, Vol. 89, No. 5, 1999, pp. 723-730. doi:10.2105/AJPH.89.5.723

[62] P. W. Goslar, C. A. Macera, L. G. Castellanos, J. R. Hussey, F. S. Sy and P. A. Sharpe, "Blood Pressure in Hispanic Women: The Role of Diet, Acculturation, and Physical Activity," Ethnicity \& Disease, Vol. 7, No. 2, 1997, pp. 106-113.

[63] C. J. Crespo, C. M. Loria and V. L. Burt, "Hypertension 
and Other Cardiovascular Disease Risk Factors among Mexican Americans, Cuban Americans, and Puerto Ricans from the Hispanic Health and Nutrition Examination Survey," Public Health Reports, Vol. 111, Suppl. 2, 1996, pp. 7-10.

[64] M. P. Stern, M. Rosenthal, S. M. Haffner, H. P. Hazuda and L. J. Franco, "Sex Difference in the Effects of Sociocultural Status on Diabetes and Cardiovascular Risk Factors in Mexican Americans. The San Antonio Heart Study," American Journal of Epidemiology, Vol. 120, No. 6, 1984, pp. 834-851.

[65] M. A. Burnam, R. L. Hough, M. Karno, J. I. Escobar and C. A. Telles, "Acculturation and Lifetime Prevalence of Psychiatric Disorders among Mexican Americans in Los Angeles," Journal of Health and Social Behavior, Vol. 28, No. 1, 1987, pp. 89-102. doi:10.2307/2137143

[66] E. Alderete, W. A. Vega, B. Kolody and S. AguilarGaxiola, "Effects of Time in the United States and Indian Ethnicity on DSM-III-R Psychiatric Disorders among Mexican Americans in California," Journal of Nervous and Mental Disease, Vol. 188, No. 2, 2000, pp. 90-100. doi:10.1097/00005053-200002000-00005

[67] P. J. Cantero, J. L. Richardson, L. Baezconde-Garbanati and G. Marks, "The Association between Acculturation and Health Practices among Middle-Aged and Elderly Latinas," Ethnicity \& Disease, Vol. 9, No. 2, 1999, pp. 166-80.

[68] V. J. Ebin, C. D. Sneed, D. E. Morisky, M. J. Rotheram-Borus, A. M. Magnusson and C. K. Malotte, "Acculturation and Interrelationships between Problem and Health-Promoting Behaviors among Latino Adolescents," Journal of Adolescent Health, Vol. 28, No. 1, 2001, pp. 62-72. doi:10.1016/S1054-139X(00)00162-2

[69] R. E. Roberts and E. S. Lee, "The Health of Mexican Americans: Evidence from the Human Population Laboratory Studies," American Journal of Public Health, Vol. 70, No. 4, 1980, pp. 375-384. doi:10.2105/AJPH.70.4.375

[70] R. E. Roberts, E. S. Lee, M. Hemandez and A. C. Solari, "Symptoms of Insomnia among Adolescents in the Lower Rio Grande Valley of Texas," Sleep, Vol. 27, No. 4, 2004, pp. 751-760.

[71] E. Alderete, W. A. Vega, B. Kolody and S. AguilarGaxiola, "Lifetime Prevalence of and Risk Factors for Psychiatric Disorders among Mexican Migrant Farmworkers in California," American Journal of Public Health, Vol. 90, No. 4, 2000, pp. 608-614.

doi:10.2105/AJPH.90.4.608

[72] O. I. Bermudez, L. M. Falcon and K. L. Tucker, "Intake and Food Sources of Macronutrients among Older Hispanic Adults: Association with Ethnicity, Acculturation, and Length of Residence in the United States," Journal of the American Dietetic Association, Vol. 100, No. 6, 2000, pp. 665-673. doi:10.1016/S0002-8223(00)00195-4
[73] R. Caetano and M. E. Mora, "Acculturation and Drinking among People of Mexican Descent in Mexico and the United States," Journal of Studies on Alcohol, Vol. 49, No. 5, 1988, pp. 462-471.

[74] J. P. Elder, F. G. Castro, C. de Moor, J. Mayer, J. I. Candelaria, N. Campbell, et al., "Differences in CancerRisk-Related Behaviors in Latino and Anglo Adults," Preventive Medicine, Vol. 20, No. 6, 1991, pp. 751-763. doi:10.1016/0091-7435(91)90069-G

[75] D. V. Espino and D. Maldonado, "Hypertension and Acculturation in Elderly Mexican Americans: Results from 1982-84 Hispanic HANES," Journal of Gerontology, Vol. 45, No. 6, 1990, pp. M209-M213. doi:10.1093/geronj/45.6.M209

[76] G. Marin, E. J. Perez-Stable and B. V. Marin, "Cigarette Smoking among San Francisco Hispanics: The Role of Acculturation and Gender," American Journal of Public Health, Vol. 79, No. 2, 1989, pp. 196-198. doi:10.2105/AJPH.79.2.196

[77] K. S. Markides, N. Krause and C. F. Mendes de Leon, "Acculturation and Alcohol Consumption among Mexican Americans: A Three-Generation Study," American Journal of Public Health, Vol. 78, No. 9, 1988, pp. 11781181. doi:10.2105/AJPH.78.9.1178

[78] R. Otero-Sabogal, F. Sabogal, E. J. Perez-Stable and R. A. Hiatt, "Dietary Practices, Alcohol Consumption, and Smoking Behavior: Ethnic, Sex, and Acculturation Differences," Journal of the National Cancer Institute. Monographs, No. 18, 1995, pp. 73-82.

[79] L. A. Palinkas, J. Pierce, B. P. Rosbrook, S. Pickwell, M. Johnson and D. G. Bal, "Cigarette Smoking Behavior and Beliefs of Hispanics in California," American Journal of Preventive Medicine, Vol. 9, No. 6, 1993, pp. 331-337.

[80] R. E. Roberts and E. S. Lee, "Medical Care Use by Mexican-Americans: Evidence from the Human Population Laboratory Studies," Medical Care, Vol. 18, No. 3, 1980, pp. 267-281. doi:10.1097/00005650-198003000-00002

[81] J. M. Solis, G. Marks, M. Garcia and D. Shelton, “Acculturation, Access to Care, and Use of Preventive Services by Hispanics: Findings from HHANES 1982-84," American Journal of Public Health, Vol. 80, Supplement, 1990, pp. 11-19. doi:10.2105/AJPH.80.Suppl.11

[82] K. B. Wells, J. M. Golding, R. L. Hough, M. A. Burnam and M. Karno, "Factors Affecting the Probability of Use of General and Medical Health and Social/Community Services for Mexican Americans and Non-Hispanic Whites," Medical Care, Vol. 26, No. 5, 1988, pp. 441452. doi:10.1097/00005650-198805000-00001

[83] M. A. Winkleby, S. P. Fortmann and B. Rockhill, "HealthRelated Risk Factors in a Sample of Hispanics and Whites Matched on Sociodemographic Characteristics. The Stanford Five-City Project," American Journal of Epidemiology, Vol. 137, No. 12, 1993, pp. 1365-1375. 